\title{
Online teaching-learning in STEM SCALE-UP classrooms during the COVID-19 pandemic: feedback from students
}

\author{
Emma Zipperer ${ }^{1}$, Nandana Weliweriya ${ }^{1},{\text { Tara } \text { Cotten }^{1}, \text { Maduranga Dassanayake }^{2} \text {, and Aravinda Karunaratne }}^{3}$ \\ ${ }^{1}$ Department of Physics \& Astronomy, ${ }^{2}$ Department of Statistics, \\ ${ }^{3}$ Department of Public Administration \& Policy, The University of Georgia, Athens, GA 30602-2451
}

\begin{abstract}
During the COVID-19 pandemic, many educators had to shift their in-person teaching to either synchronous instruction using hybrid methods or asynchronous delivery with HyFlex models. In synchronous models, educators had to master many online tools to instruct and engage their students throughout the pandemic. Students may find online instruction an additional challenge beyond the typical academic demands of student lives. To grasp the problems students face, a team of STEM faculty members studied student feedback surveys related to online instruction. We focused specifically on the SCALE-UP (Student-Centered Active Learning Environment with Upside-down Pedagogies) classroom model designed for "group-based" learning. The study investigates how hybrid instruction during the pandemic has affected students' study strategies, motivations, and group work in STEM SCALE-UP classrooms. We inquired students' preferred methods for group activities, their tendencies to participate in in-person group activities, and their concerns on privacy and camera usage. We also evaluated the emotional toll of online instruction on instructor-student relationships. Another factor we assessed was students' inclination to accessing unauthorized web-based assistance providers. This study has three primary aims. They are, understanding students' experiences of the transition from face-to-face to online learning, conducting an analysis of strengths and weaknesses/challenges of online learning during the pandemic, and offering suggestions and recommendations for the success of online learning modes during a crisis.
\end{abstract}




\section{INTRODUCTION}

In spring 2020, due to the coronavirus outbreak, many colleges and universities closed their in-person operations and were forced to continue remotely. Neither educators nor students were prepared for this short-notice transition. As a result, both parties faced various challenges as they advanced through the following semesters. Educators and students were unprepared for this need for emergency remote teaching (ERT) and were often not equipped with digital resources, including but not limited to required devices and decent internet connections. Furthermore, all instructor-student communication was limited to learning management systems that were not initially planned for online or remote learning. The presence of all these limitations posed significant barriers to students in accessing quality education.

There are many ways to deliver instruction in an online format, but the main two categories are synchronous or asynchronous. Asynchronous instruction does not require realtime interaction, and students can complete the course according to their own schedules. During the early stages of the pandemic, i.e., the latter portion of the spring 2020 semester, instructors commonly used this method, providing prerecorded lecture videos and lecture notes, readings, assignments, and online exams. In asynchronous instruction, although the course content is available for students to access according to their own schedules, they must nonetheless complete assignments within the deadlines set by instructors. In contrast, synchronous instruction has multiple options for instructor-student interactions. Synchronous instruction is typically delivered through various live video chat platforms, through which the students must attend classes in real time. The goal of this approach is to simulate a real classroom experience through online, distance learning. Although these comprise the two main categories, a hybrid (also referred to as blended or mixed) approach is also possible. The goal of this approach modelled students participating in distance learning synchronously online part of the time and face-toface instruction for the remainder.

One study that evaluated the effectiveness of synchronous vs. asynchronous learning in introductory-level calculusbased physics classes [1] found that those who attended synchronous lectures achieved better grades and assessment scores than those who watched the asynchronous lectures. This study further [1] recommends mandatory synchronous attendance; however, other research suggests that this policy might be unfavorable. Perets et al. [2] recommend implementing a semi-mandatory attendance policy to increase student engagement while also allowing flexibility and understanding during unprecedented times. Similarly, Wilcox et al. [3] found that synchronous learning leads to better student engagement by enabling students to ask questions and actively learn. Moreover, they discovered that asynchronous learning allowed more flexibility but found that students who were learning primarily through this approach were less motivated, and minimal student interaction occurred [3].
The hybrid model seemed to be the most effective approach to distance learning during the COVID-19 pandemic, and it was adopted by the university where this study was carried out well into the fall 2020 and spring 2021 semesters. For our research purposes, we examined introductory physics courses that mostly adopted hybrid models for instruction. Students were given the option to attend lectures in person or synchronously through the Zoom platform. It is important to note that in-person attendance was limited by classroom size and distancing requirements, and students were only allowed to participate through in-person instruction once a week due to the CDC guidelines in place. This situation required the instructors to make classroom instruction equally accessible for the students attending in-person and online during class. Therefore, the instructor also had to be aware of how the material was presented both in person and online. Furthermore, departments encouraged instructors to record and post lectures to accommodate students facing illness, connectivity issues, and other pandemic-related issues.

Another study [6] evaluating the effects of the pandemic on learning found a nearly $200 \%$ increase in question submissions to Chegg, an online platform that helps students with their assignment problems, during the COVID-19 pandemic. The authors suspect that this increase in requests is linked to cheating, since students can submit their problem(s), and receive a timely solved response. If this suspicion holds, the students may not be attempting the problems themselves. This trend is detrimental to their learning experience, as relying too much on others impedes active learning. A link to understanding why students turn to this platform may be found through the investigation of student responses to pandemic challenges.

Our focus for the study is SCALE-UP (Student-Centered Active Learning Environment with Upside-down Pedagogies) classrooms in STEM courses. These are interactive classrooms that facilitate the use of "group-based" learning. Here, the students form groups, work on a problem, and then find the answer with the help of their partners, the instructor, and other groups. This setup is often called a "flipped" classroom because it flips the way standard instruction is presented. The students must take responsibility to learn, or familiarize themselves with, the information before attending lectures on a given day. Here in our department, the SCALEUP physics classrooms are equipped with eight round tables. Each table accommodates nine students, who belong to three groups of three. This layout allows a less crowded workspace for the students while optimizing the overall classroom space.

In previous semesters, the SCALE-UP classrooms have been aided by peer learning assistants (PLAs). The PLAs are students who have taken the same class in a previous semester and can assist students when the instructor cannot. Peer instruction helps students understand concepts better and actively participate with their peers through collaborative learning.

SCALE-UP classrooms have been found to increase conceptual understanding, improve student attitudes, and result 
in higher overall success rates or decreased failure rates in lower-level STEM classes [4]. We wanted to determine if this approach is still valid and investigate how the translation to hybrid teaching works within SCALE-UP courses. This study 's main objectives are a.) understanding students' experiences of transitioning from face-to-face to online learning, b.) conducting a strengths weaknesses/challenges analysis of online learning during the COVID-19 pandemic, and c.) offering some suggestions for approaching online learning in a pandemic-like situation.

\section{METHODS}

This research was carried out at the university of Georgia, Athens. The data for this study were collected from introductory-level STEM courses in SCALE-UP classrooms in which group-based learning is prevalent. In both semesters, fall 2020 and spring 2021, we collected survey responses from 11 STEM courses, although we had the opportunity to collect data from just three non-physics courses. The survey was distributed to students enrolled in Physics, Chemistry, Biochemistry, Pharmacy, and Statistics classes. The survey response rate was approximately $42 \%$ for non-physics courses and approximately $72.9 \%$ for the physics courses.

The survey, built in the Qualtrics environment, included multiple-choice and open-response questions about camera usage through personal device and privacy, preferred delivery of group activities, and their participation tendencies. Other questions addressed the emotional toll on both students and instructors and ways to help increase student engagement for hybrid distance learning amidst a global pandemic.

\section{ANALYSIS}

\begin{tabular}{|l|c|c|}
\hline \multicolumn{1}{|c|}{ Question } & \multicolumn{2}{|c|}{ Yes - (\%) } \\
\cline { 2 - 3 } & Fall 2020 & Spring 2021 \\
\hline Did you attend in-person lectures? & $48.33 \%$ & $47.68 \%$ \\
\hline $\begin{array}{l}\text { Did you attend synchronous Zoom } \\
\text { lectures? }\end{array}$ & $99 \%$ & $90.54 \%$ \\
\hline $\begin{array}{l}\text { Was the material discussed during the } \\
\text { lectures explained clearly? }\end{array}$ & $74.64 \%$ & $83.57 \%$ \\
\hline $\begin{array}{l}\text { Were the clicker questions (stop-and- } \\
\text { think) helpful to your understanding? }\end{array}$ & $65.07 \%$ & $64.64 \%$ \\
\hline $\begin{array}{l}\text { If you did not attend in-person lectures } \\
\text { or synchronous Zoom lectures, did you } \\
\text { watch asynchronous (recorded) Zoom } \\
\text { lectures? }\end{array}$ & $60.29 \%$ & $88.5 \%$ \\
\hline
\end{tabular}

Table 1: Lecture attendance and related questions

\begin{tabular}{|c|c|c|c|c|}
\hline & \multirow[b]{2}{*}{ Count } & \multicolumn{3}{|c|}{$\begin{array}{l}\text { Did you attend office } \\
\text { hours with the } \\
\text { instructor? }\end{array}$} \\
\hline \multirow{9}{*}{$\begin{array}{l}\text { Did you work with a } \\
\text { tutor (either from } \\
\text { UGA or outside), } \\
\text { how often? }\end{array}$} & & No & Yes & Total \\
\hline & 1-2 hours every week & 32 & 13 & 45 \\
\hline & $\begin{array}{l}\text { 1-2 times per every } \\
\text { month }\end{array}$ & 11 & 4 & 15 \\
\hline & $\begin{array}{l}\text { 1-4 times during the } \\
\text { semester }\end{array}$ & 18 & 18 & 36 \\
\hline & $\begin{array}{l}\text { I did not work with a } \\
\text { tutor }\end{array}$ & 466 & 160 & 626 \\
\hline & $\begin{array}{l}\text { One time before each } \\
\text { midterm exam }\end{array}$ & 10 & 5 & 15 \\
\hline & $\begin{array}{l}\text { One time every two } \\
\text { weeks }\end{array}$ & 6 & 9 & 15 \\
\hline & Other & 11 & 5 & 16 \\
\hline & Total & 554 & 214 & 768 \\
\hline
\end{tabular}

Table 2: Students working with a tutor

Through an extensive quantitative analysis, we found an association between attending in-person classes and student feedback on whether the lectures were explained clearly. Students who attended in-person lectures found that the lectures were explained concepts more clearly than those who did not $(p$-value $=0.002)$. There was a significant increase $\left(\chi^{2}=\right.$ 8.216; $d f=2$; $p$-value $=0.0164)$ in the percentage of students who thought that the material discussed during the lectures was well explained compared to fall 2020. However, most students (more than 50\%) still thought that too few examples were discussed during the lectures.

Table 1 above summarizes the responses to selected survey questions for fall 2020 and spring 2021. Since the instructors and the classes from which the data originated remained the same, we could safely assume that the instructional methods employed in spring 2021 were similar to those in fall 2020. As evident from Table 1, less than $50 \%$ of the students attended in person, and " $1-3$ days per month" (16.75\% - fall $2020,10.89 \%$ - spring 2021) to be the most popular response.

In contrast, synchronous Zoom lecture attendance was considerable. However, the overall attendance showed a decreasing trend. One factor that may be associated with this attendance decrease is shifts in students' employment schedules. A higher percentage of students who did not attend the inperson or Zoom lectures were employed. The majority of the students $(57.68 \%)$ who attended in-person lectures and most students who attended Zoom lectures $(56.41 \%)$ were unemployed. Initial personal conversations with students led us to believe that students may be choosing employment over class attendance but then we found no association $\left(\chi^{2}=0.535\right.$; $d f=1 ; p$-value $=0.4646)$. Similarly, the association between work and Zoom lecture attendance was not statistically significant $\left(\chi^{2}=0.25 ; d f=1 ; p\right.$-value=0.6173). Moreover, the students who watched asynchronous (recorded) Zoom lectures showed a considerable increase in attendance. An attendance policy that is not mandatory appears to harm the motivation 
for synchronous attendance.

Furthermore, most students stated that they did not work with a tutor during the fall 2020 and spring 2021 semesters. Table 2 shows that out of 626 students, $74.4 \%$ did not work with a tutor. The majority of students also did not attend office hours with their instructor. Since we do not have access to their grades, we are uncertain how this choice affected student outcomes, and conclusions cannot be generalized.

Additionally, we performed strengths \& weaknesses/challenges analysis using hybrid SCALE-UP classrooms for introductory physics classes based on survey input data from fall 2020 and spring 2021 semesters. One of the challenges most students stated was that they did not like having to engage in online group work. However, our results also show that most students agree that group work does support their learning style (Figure 1). We believe that this discrepancy is associated with the instructor's inability to regulate group work and student contribution. Students also stated that they found it difficult to ask questions while attending online synchronous Zoom lectures. Furthermore, students found open-note/book exams helpful if they had studied but not helpful if they had not. However, many students reported that open-note/book exams reduced their stress levels. In contrast, $65 \%$ of students found the clicker questions presented during class to be helpful in their ability to learn. Another strength found was that the hybrid model allowed students more flexibility with their time.

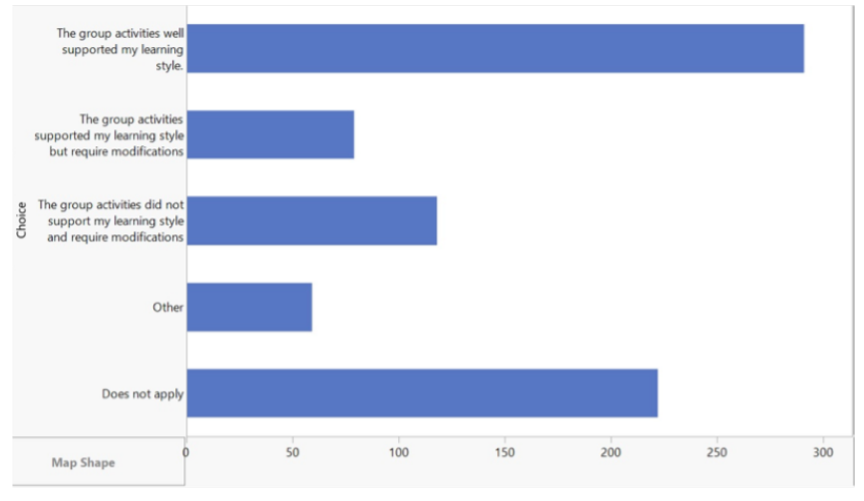

FIG. 1. Student responses about group activities during the semester

\section{DISCUSSION AND CONCLUSION}

Distance teaching requires the careful consideration, planning, and development of technological and human resources to successfully achieve the desired learning outcomes. College administrators have the arduous task of determining the best way to move their campuses forward during uncharted times. They need to navigate protecting the health and safety of the campus and neighboring community while also advancing the educational mission, the research enterprise, and the financial stability of the institution. Campus decision-makers are operating with little precedent, and there are few easy answers or solutions in the face of the continued COVID-19 crisis. Nonetheless, institutions now have the advantage of lived experience to help them anticipate and better prepare to meet students' health and academic needs, regardless of where students may be physically located. We offer these recommendations.

Studies have reported [2] that student engagement decreased after the transition to online instruction but have also found that assignments that did not require classroom attendance increased student engagement in the class. Furthermore, under pressure to rapidly put their course materials online [5], instructors modified their courses to include online busywork that did not constitute meaningful learning activities, which had a detrimental effect on student outcomes at scale. These findings are discussed in contrast with other situations in which increased engagement does not necessarily lead to improved learning outcomes, and in comparison with the broader relationship between effort and academic achievement. Most students who participated in our study neither attended office hours nor sought additional help from a tutor. These phenomena could be due to a lack of motivation or the widespread availability of online resources. We suggest creating a flipped-classroom approach, or an approximation of it, in which the students watch short videos, read sections of the textbook, and answer a few problems before attending either an in-person or synchronous online lecture. This approach would allow students time to digest and study the information before attending class and applying it. We suggest that such an approach will help promote student engagement in synchronous instructions in a crisis-like situation and even in those face-to-face instructional situations that may be moving toward in-person instruction again. Students in our survey who attended synchronous instruction stated that they would like instructors to encourage or mandate having webcams turned on. This requirement would be an effective way to monitor student engagement and simulate a "regular" classroom experience.

In conjunction with the flipped hybrid SCALE-UP approach, we recommend using peer learning assistants (PLAs). In Figure 1, the majority of students stated that group activities supported their learning style. The implementation of PLAs can help support students' learning styles through group activities. Students can use breakout rooms on Zoom or whiteboards in the classroom to collaborate. The PLAs can participate by visiting these groups to serve as a liaison for the instructor. We also recommend peer learning assistants host a version of office hours - either in large groups or by individual appointment - during which students can receive peer help. Peer office hours would help both the students and the instructor because many students in our report stated that they found it difficult to ask questions during synchronous lectures. Many students also commented that they wanted to work out more problems in class using different 
variations of real-world examples. We believe that further quantitative analysis of this finding would support our idea of implementing a hybrid flipped classroom approach but with limited classroom hours, PLAs may be a useful solution.

Before pandemic, during face-to-face instructions, the instructors or PLAs could walk around the room and monitor student activities in face-to-face instruction, ultimately leading to improved academic achievements. In contrast, studies [7] report students complaining about online classes being too much work. This may be because instructors were under pressure to quickly shift their in-person teaching to online methods and send out as many online learning activities to keep students engaged. As a result, students may be viewing class time as busy work rather than actively engaging in the learning process. Complicating students' requests to solve more problems is the suspicion of using third-party online solution platforms such as Chegg [6]. We suspect that students' widespread access to these platforms also decreases their engagement in online instruction since they may search for the practice questions presented in class before working on them by themselves.

To increase student engagement with problem-solving and trying different ways of solving a given problem, we suggest that instructors use Pencast [8] submissions to collect student work and gauge whether the students understand the material. Pencasts are video recordings of a student explaining their problem-solving process step by step. Pencasts provide insight into how the student solves the problem through gestures, free-body diagrams, equations, and narrations. In our study, students reported that they did not enjoy group work while in Zoom breakout rooms; however, the majority stated that group activities did support their learning style (Figure 1). Because Pencasts can be made individually or in groups, they can assist students at both ends of the spectrum of preferences for problem work.

Students' inability to engage during distance learning is a common issue with synchronous online instruction. Students join Zoom lectures from various locations, such as workplaces, library study rooms, coffee shops, and even from their beds and the driver seats of moving vehicles [9]. The lack of a proper setting for learning hinders their engagement. These unhelpful background locations seem to prompt students to turn off their cameras and mics to prevent connecting with peers and instructors. In such cases, we find that the Zoom chat provides an additional layer of communication that can help replicate in-person situations, whether it be a student asking or answering a question, introducing an idea to the group, or even whispering to a peer. Along with this idea, when instructors ask students to use Zoom chat to send their responses to large-group and whole-class discussions, we find that peer ideas are influencing students, thereby preventing us from seeing a range of student answers. Students who send their answers quickly influence the thoughts and responses of the other students, who may be taking a little longer to figure out the answers. As a solution, we suggest that instructors use a step-by-step approach to these activities that allows students to send their answers only within a given time window. Instructors can post the problem and provide a few minutes to work on the it, with the instructions that students not send their answers until the time has elapsed. When the time is up, the instructor can say something like, "Now, type your answer, but do not send it yet". After 10-15 seconds, the instructor can say, "Now hit enter and send me your answers". This approach worked well during the fall 20 and spring 21 semesters with our Calculus-based Physics 1 and 2 courses.

Our survey results show that almost all students had their cameras turned off during most of the lecture time and even within the breakout rooms, where they were required to work with peers to solve problems or work on labs. Also, we have confirmed this with the instructors in these courses. In order to overcome this limitation of unhelpful background locations hindering student engagement, we suggest that if the instructors could ask background for every student in the class. Such that their cameras are forced to be on, but it's "green-screened" or whatever, and everyone sees each other's faces and not the background, then it would solve the strange "where-are-you-right-now" issue.

Only approximately $27 \%$ of our survey responses represent the non-physics SCALE-UP courses, and these courses also had a low response rate. This low response rate may be because almost all the physics instructors offered extra credit for completing the survey, while few non-physics instructors did so. Despite this limitation, we believe these students' survey responses represent a sufficient sample of undergraduate STEM students to generalize our findings.

Given the results found in this study, we hope to continue investigating the online teaching and learning of students during COVID-19 through the creation of personas. Personas are life-like models of students dictated by various motivators and goals that can be applied in real life to students and their learning styles. These personas will allow instructors to tailor their teaching to better aid each persona's learning style and further engage their students. However, these personas can be implemented in classrooms to create an educational plan that accurately fits students' needs, even within in-person instruction. This approach allows for classes to be catered to the students, helping them gain the necessary information efficiently and effectively while placing them in groups in which they will fit best to complete problem-solving activities and experiments.

\section{ACKNOWLEDGEMENT}

The research team would like to thank all the faculty members and students who helped us collect the survey responses. 
[1] Guo, S. (2020). Synchronous Versus Asynchronous Online Teaching of Physics During the COVID-19 Pandemic. Physics Education, 55(6).

[2] Perets, E. A., Chabeda, D., Gong, A. Z., Huang, X., Fung, T. S., Ng, K. Y., Bathgate, M., Yan, E. C. Y. (2020). Impact of the Emergency Transition to Remote Teaching on Student Engagement in a Non-STEM Undergraduate Chemistry Course in the Time of COVID-19. Journal of Chemical Education, 97(9), 2439-2447.

[3] Wilcox, B., Vignal, M. (2020). Recommendations for Emergency Remote Teaching Based on the Student Experience. The Physics Teacher, 58(6), 374-375.

[4] Beichner, R. J., Saul, J. M., Abbott, D. S., Morse, J. J., Deardorff, D., Allain, R. J., ... Risley, J. S. (2007). The student-centered activities for large enrollment undergraduate programs (SCALE-UP) project. Research-based reform of university physics, 1(1), 2-39.

[5] Motz, B. A., Quick, J. D., Wernert, J. A., Miles, T. A. (2021). A Pandemic of Busywork: Increased Online Coursework Fol- lowing the Transition to Remote Instruction Is Associated with Reduced Academic Achievement. Online Learning, 25(1), 7085.

[6] Lancaster, T., Cotarlan, C. (2021). Contract cheating by STEM students through a file sharing website: a Covid-19 pandemic perspective. International Journal for Educational Integrity, 17(1), 1-16.

[7] Motz, B. A., Quick, J. D., Wernert, J. A., Miles, T. A. (2021). A Pandemic of Busywork: Increased Online Coursework Following the Transition to Remote Instruction Is Associated with Reduced Academic Achievement. Online Learning, 25(1), 7085.

[8] Weliweriya, N., Sayre, E. C., Zollman, D. A. (2018). The Effectiveness of "Pencasts" in Physics Courses. The Physics Teacher, 56(3), 161-164.

[9] Hammond, C. (2020). Online Education in the Time of COVIDâa Political Science Student's Perspective. In Tertiary Online Teaching and Learning (pp. 233-236). Springer, Singapore. 